\title{
Esophageal self-expanding metallic stent (SEMS) migration: it's a topsy-turvy world
}

A 47-year-old woman underwent endoscopic treatment of a fistula following sleeve gastrectomy, performed 3 weeks earlier. A partially covered self-expandable metallic stent (SEMS) was inserted $(15 \mathrm{~cm}, \quad 18-23 \mathrm{~mm}$ Ultraflex, Boston Scientific, Natick, Massachusetts, USA). At 1 month follow-up she was symptomfree. Radiographic examination and computed tomography ( $\bullet$ Fig. 1) showed that the stent had partially migrated distally, and there was no collection. The patient became aphagic 6 days before her scheduled admission for retrieval of the partially covered SEMS. Endoscopy revealed that the stent had bent and "re-migrated" proximally, into the mid-esophagus, thus causing complete obstruction ( $\mathbf{F i g} \mathbf{2}$ ). The stent was retrieved using rat-tooth forceps, and the patient was discharged the next day. She remains symptom-free. Leaks complicate bariatric surgery in $2.4 \%-4.9 \%$ of cases [1-3]. Endoscopic placement of self-expandable stents is a well-recognized part of leak management and leads to successful closure in $87.7 \%$ [4]. Among the most frequent complications of SEMS insertion is stent migration (11.1\%) and stenosis caused by hyperplasia $(11.1 \%)$ [5]. This rate of migration is related to the design of the stents, which is based on their use in stricture management. In the absence of stenosis, the incomplete contact between the mucosa and the stent may lead to migration. Hyperplasia following insertion of partially covered SEMS helps to decrease the risk of migration [4].

In the present case, we found a stent folded onto itself in the esophagus, and radiographs showed that the upper part of the stent was located distally. We speculate that after the stent migrated into the gastric sleeve ( Fig.3), it was partially repositioned nearly horizontally, after which it folded onto itself and migrated proximally into the esophagus, where it caused complete obstruction. This may be explained by narrowing of the gastric body following the sleeve, which could hinder distal migration in the antrum.

Endoscopy_UCTN_Code_CPL_1AH_2AD

Competing interests: None

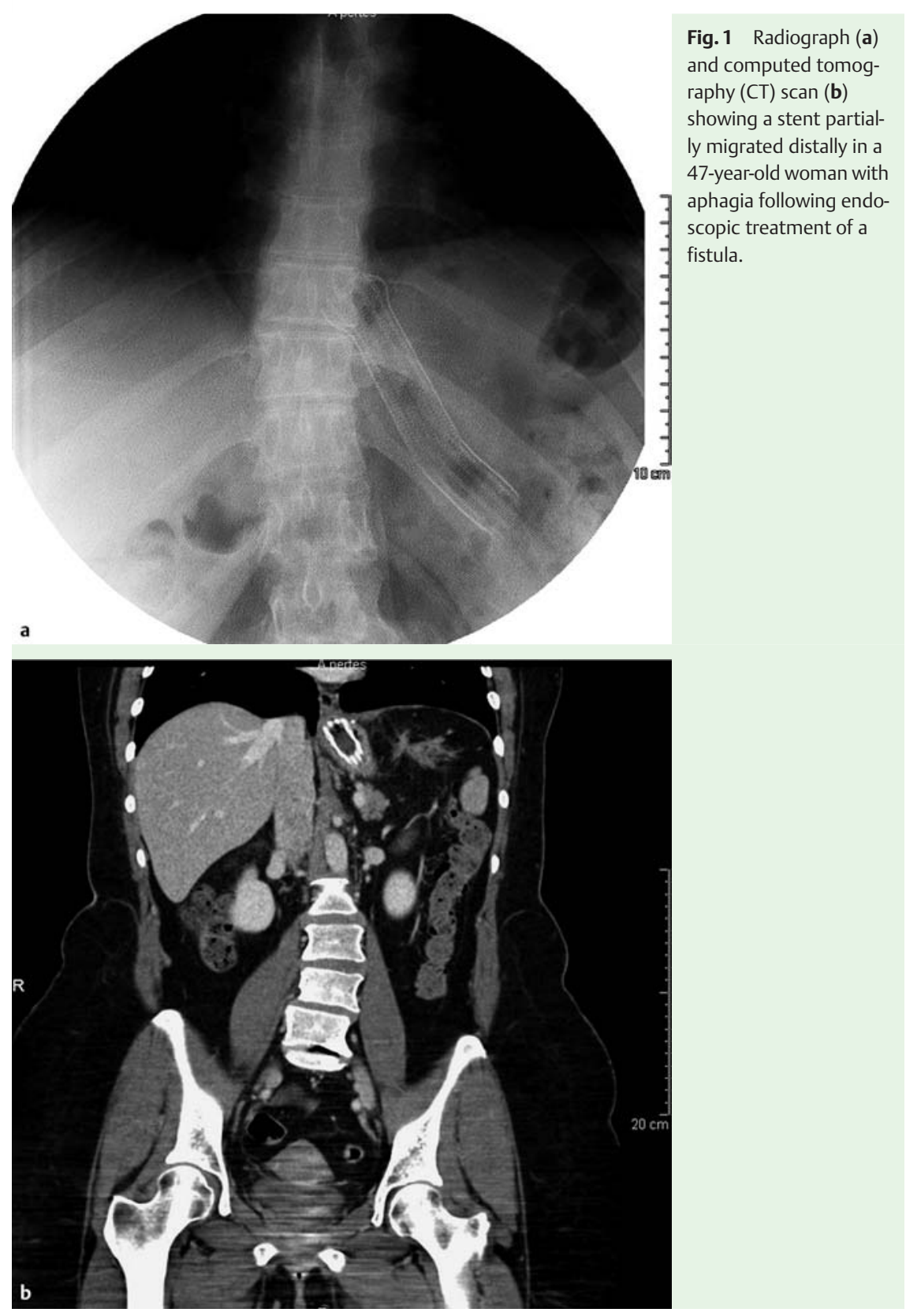

\section{E. Toussaint ${ }^{1}$, M. Zalcman ${ }^{2}$, J. Devière ${ }^{3}$, O. Le Moine ${ }^{3}$, M. Arvanitakis ${ }^{3}$}

${ }^{1}$ Medicine Department, Jules Bordet Institute, Brussels, Belgium

${ }^{2}$ Department of Radiology, Erasme University Hospital, Université Libre de Bruxelles, Brussels, Belgium

${ }^{3}$ Medical Department of Gastroenterology, Erasme University Hospital, Université Libre de Bruxelles, Brussels, Belgium 

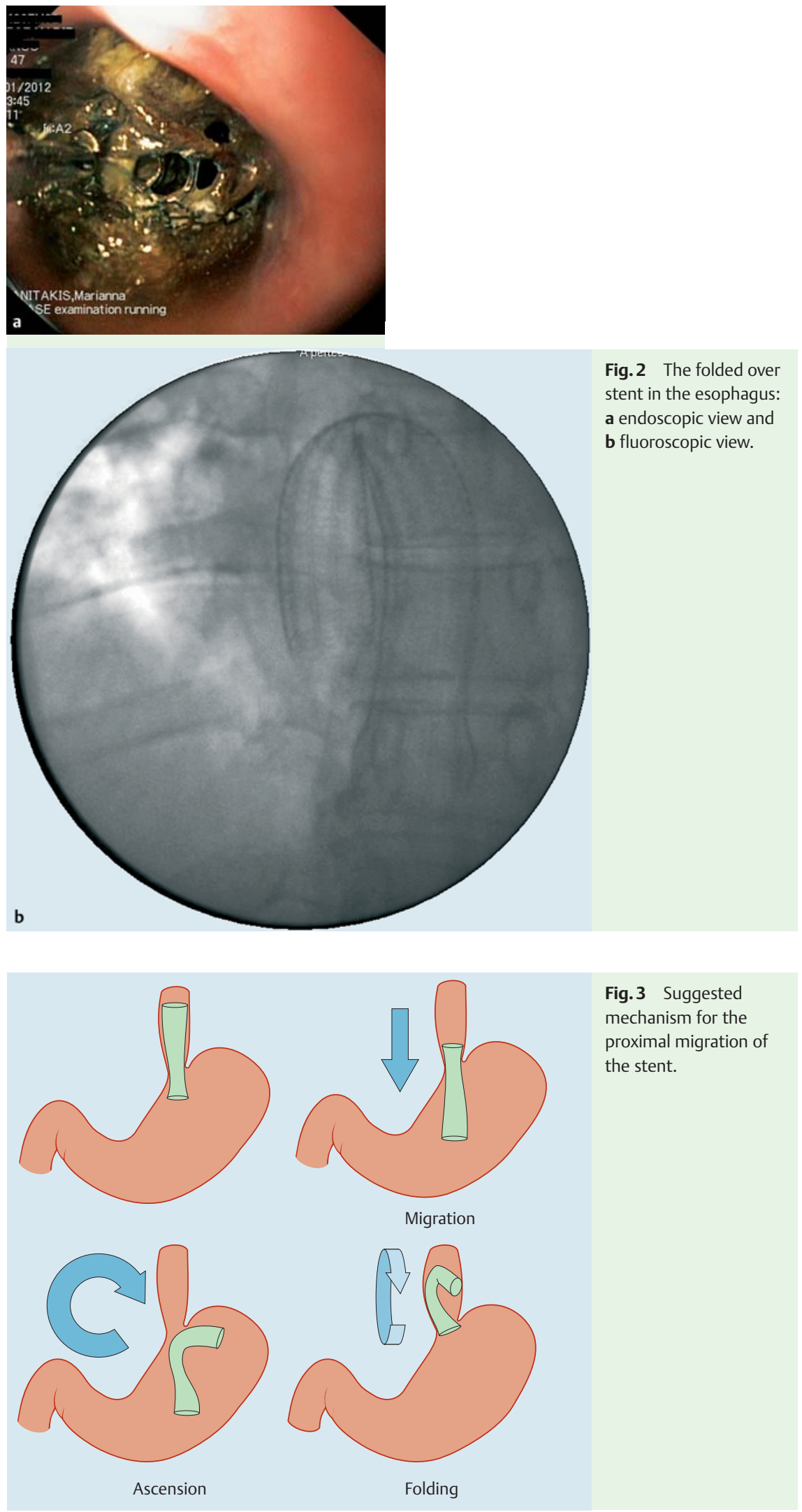

\section{References}

1 Fernandez AZ Jr, DeMaria EJ, Tichansky DS et al. Experience with over 3,000 open and laparoscopic bariatric procedures: multivariate analysis of factors related to leak and resultant mortality. Surg Endosc 2004; 18 (Suppl. 02): $193-197$

2 Ballesta $C$, Berindoague $R$, Cabrera $M$ et al. Management of anastomotic leaks after laparoscopic Roux-en-Y gastric bypass. Obes Surg 2008; 18 (Suppl. 06): 623-630

3 Aurora AR, Khaitan L, Saber AA. Sleeve gastrectomy and the risk of leak: a systematic analysis of 4,888 patients. Surg Endosc 2011; 26: 1509-1515

Fig. 2 The folded over stent in the esophagus: a endoscopic view and b fluoroscopic view.

Puli SR, Spofford IS, Thompson CC. Use of selfexpandable stents in the treatment of bariatric surgery leaks: a systematic review and meta-analysis. Gastrointest Endosc 2012; 75 (Suppl. 02): 287-293

5 Swinnen J, Eisendrath P, Rigaux J et al. Selfexpandable metal stents for the treatment of benign upper GI leaks and perforations. Gastrointest Endosc 2011; 73 (Suppl. 05): 890-899

\section{Bibliography}

DOI http://dx.doi.org/

10.1055/s-0032-1310025

Endoscopy 2012; 44: E352-E353

(c) Georg Thieme Verlag KG

Stuttgart · New York

ISSN 0013-726X

\section{Corresponding author}

\section{E. Toussaint}

Medicine Department

Jules Bordet Institute

1 , rue Heger-Bordet

1000 Brussels

Belgium

Fax: +322-538-0858

emmanuel.toussaint@bordet.be 